\title{
]jfis
}

\section{Observer-Based FL-SMC Active Damping for Back-to-Back PWM Converter with LCL Grid Filter}

\author{
Jin-Su Gwon ${ }^{1,2}$, Hansoo Lee ${ }^{2}$, and Sungshin Kim ${ }^{2}$ \\ ${ }^{1}$ HVDC Research Devision, Korea Electrotechnology Research Institute, Changwon, Korea \\ ${ }^{2}$ Department of Electrical Engineering, Pusan National University, Busan, Korea
}

\begin{abstract}
This paper proposes an active damping control method for a grid-side converter that has an LCL grid filter in the back-to-back converter. To remove the resonant frequency components produced by the LCL filter, it is necessary to measure the grid current. To do this, sensors must be added. However, it is not necessary to add sensors because the grid current is estimated by designing a suboptimal observer. In order to remove the nonlinearity and to gain fast response of control, both feedback linearization and sliding mode control are applied. The proposed method is verified through a simulation.
\end{abstract}

Keywords: PWM converters, FL-SMC control, Suboptimal observer, Kalman filter, Total harmonic distortion, Power quality.

\section{Introduction}

Research related to renewable energy has been conducted in recent years owing to elevated interest in energy such as wind power, solar power, tidal current, and wave power because of the possible exhaustion of fossil fuels. Typically, wind power generation uses the following process: a turbine converts wind energy to mechanical energy, and generators convert mechanical energy to electric energy. The electricity produced by the generators is connected to the grid side by a power converter device [1].

A power converter device is composed of a back-to-back PWM converter that consists

Received: Aug. 172015

Revised : Sep. 23, 2015

Accepted: Sep. 24, 2015

Correspondence to: Sungshin Kim

(sskim@pusan.ac.kr)

(CThe Korean Institute of Intelligent Systems

cCThis is an Open Access article distributed under the terms of the Creative Commons Attribution Non-Commercial License (http://creativecommons.org/licenses/ by-nc/3.0/) which permits unrestricted noncommercial use, distribution, and reproduction in any medium, provided the original work is properly cited. of two converters: a generator-side converter, which turns over the energy produced from generators to the grid; and a grid-side converter that consistently controls both the DC-link voltage and the power factor (PF). In the conventional method, the ripple that occurs from switching is eliminated by applying an L filter to the grid-side converter. However, the methods using an L filter have disadvantages. For example, when a small L filter is used, it generates EMI in the device connected to the grid. If a large L filter is used, it increases the device volume and price, and worsens the dynamic characteristics. Therefore, an LC filter and an LCL filter are introduced by combining L and C. The LCL filter can produce excellent filter effects by using a small L filter. However, it makes the PF of the grid side worse owing to a resonance problem and a reactive current from the grid side to the filter capacitor [1-3].

There are various ways to solve these resonance problems. Generally, the resonance is removed by combining a damping resistor with the filter capacitor serially $[4,5]$. However, 
the damping resistor causes loss, lowering the efficiency of the system. Thus, various active damping methods have been proposed. Considering that active damping methods control the current so that it has the difference of $180^{\circ}$ status of the resonance components, it is required to satisfy the excellent dynamic characteristics of control. If the low dynamic characteristics cannot make the phase fit, serious problems can cause the system to diverge.

In order to control the PF of the grid side, it is necessary to have a controller that provides reactive current from the converter side provided from grid side to the filter capacitor. It is possible to calculate the value of the reactive current provided to the filter capacitor. However, if it is possible to determine the grid current, then effective control of the PF of the grid side is possible by controlling the reactive current of the grid current at zero and letting the converter provide reactive current to the filter capacitor.

The grid current ought to be informed in order to control the PF of the active damping and the grid side. In order to determine the current of the grid, it is possible to estimate the grid current by adding a current sensor or designing an observer. The two representative methods for estimating the grid current are as follows: first, use the converter current and the filter capacitor voltage; second, design the observer by applying a Kalman filter [6, 7]. However, since the method that uses a Kalman filter needs a significant operational quantity, a method for reducing the operational quantity is required.

This paper combines feedback linearity with a sliding mode control to remove the nonlinearity of the system and increase the response of the control. In addition, in order to decrease the operation quantity, the sensor is not added with estimating the grid current and applying a suboptimum observer.

Section 2 explains the modeling of the LCL filter. Section 3 describes the FL-SMC resonant control with an observer as follows: Section 3.1 explains feedback linearization, Section 3.2 explains the sliding mode control, Section 3.3 explains the determination of the stability in the controller, and Section 3.4 explains the suboptimum observer. Section 4 shows the results of the simulation. Finally, Section 5 presents the conclusion.

\section{LCL Filter Modeling}

Figure 1 is an equivalent circuit of the LCL filter, and it can be expressed in voltage equations as follows [8]:

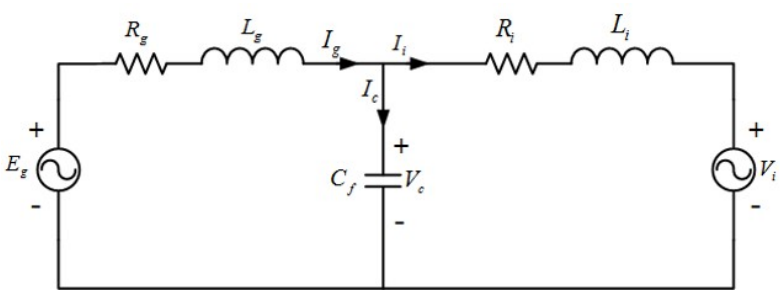

Figure 1. Simplified LCL filter equivalent circuit.

$$
\begin{aligned}
\frac{d}{d t} i_{i d} & =-\frac{R_{i}}{L_{i}} i_{i d}-\frac{1}{L_{i}} V_{i d}+\frac{1}{L_{i}} V_{c d}+\omega \cdot i_{i q} \\
\frac{d}{d t} i_{i q} & =-\frac{R_{i}}{L_{i}} i_{i q}-\frac{1}{L_{i}} V_{i q}+\frac{1}{L_{i}} V_{c q}-\omega \cdot i_{i d} \\
\frac{d}{d t} i_{g d} & =-\frac{R_{g}}{L_{g}} i_{g d}+\omega \cdot i_{g q}-\frac{1}{L_{g}} V_{c d}+\frac{1}{L_{g}} E_{g d} \\
\frac{d}{d t} i_{g q} & =-\frac{R_{g}}{L_{g}} i_{g q}-\omega \cdot i_{g d}-\frac{1}{L_{g}} V_{c q}+\frac{1}{L_{g}} E_{g q} \\
\frac{d}{d t} V_{c d} & =\frac{1}{C_{f}} i_{g d}-\frac{1}{C_{f}} i_{i d}+\omega \cdot V_{c q} \\
\frac{d}{d t} V_{c q} & =\frac{1}{C_{f}} i_{g q}-\frac{1}{C_{f}} i_{i q}-\omega \cdot V_{c d}
\end{aligned}
$$

where $V_{i d}$ and $V_{i q}$ are the voltages of the $d$-axis and $q$-axis of the converter, respectively; $i_{i d}$ and $i_{i q}$ are the currents of the $d$-axis and $q$-axis of the converter; $E_{g d}$ and $E_{g q}$ are the voltages of the $d$-axis and $q$-axis of the grid, respectively; $i_{g d}$ and $i_{g q}$ are the currents of the $d$-axis and $q$-axis of the grid; $V_{c d}$ and $V_{c q}$ are the voltages of the $d$-axis and $q$-axis of the filter capacitor; $L_{i}$ and $R_{i}$ are the inductance and resistance of the converter side; $L_{g}$ and $R_{g}$ are the inductance and resistance of the grid side; $C_{f}$ is the filter capacitance; and $\omega$ is the angular frequency.

The transfer function between the converter voltage and the filter capacitor can be expressed as follows [9], [10]:

$$
\frac{I_{c}(s)}{V_{i}(s)}=\frac{1}{L_{i} C} \frac{1}{S^{2}+\omega_{r e g}^{2}}
$$

The resistance component is ignored here, and

$$
\omega_{\text {reg }}=\sqrt{L_{g}+L_{i} / L_{g} L_{i} C}
$$

is the resonance frequency component.

In order to analyze the effect of the resonance frequency component on the grid current, the transfer function between the converter voltage and the grid current can be expressed as 


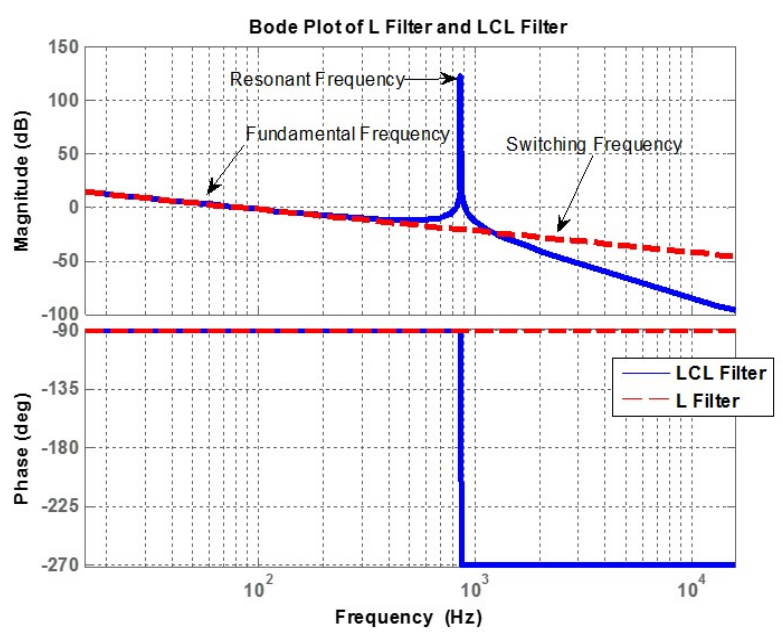

Figure 2. Bode plot of L filter \& LCL filter.

follows, ignoring the resistance component:

$$
H(s)=\frac{I_{g}(s)}{V_{i}(s)}=\frac{1}{s_{3}\left(L_{g} L_{i} C_{f}\right)+s\left(L_{g}+L_{i}\right)}
$$

Figure 2 shows a 2.0-mH L filter, $1.0 \mathrm{mH}, 22.5 \mathrm{uF}, 1.0 \mathrm{mH}$ and the Bode plot of the LCL filter in equation (3), which shows an excellent screening performance of the LCL filter. but it is possible to confirm that the resonance frequency component reveals. Because of the resonance frequency component, the total harmonic distortion (THD) becomes worse. This causes a low PF on the grid side since the reactive current is input to the filter capacitor.

\section{FL-SMC Resonant Control with Observer}

Figure 3 is a control block diagram of control method of an observer-based FL-SMC. In equation (1), the current controller can be designed as a type of PI controller by using the differential equation of the converter current.

$$
\begin{aligned}
& V_{i d}=-P I\left[i_{i d}^{*}-i_{i d}\right]+\omega \cdot L_{i} \cdot i_{i q}+V_{c d} \\
& V_{i q}=-P I\left[i_{i q}^{*}-i_{i q}\right]-\omega \cdot L_{i} \cdot i_{i d}+V_{c q}
\end{aligned}
$$

Herein, the controller for reducing the resonance frequency component is designed by using the differential equation of the grid current of equation (1). At this point, by combining feedback linearization with a sliding mode control, nonlinearity is reduced and quick control response is achieved.

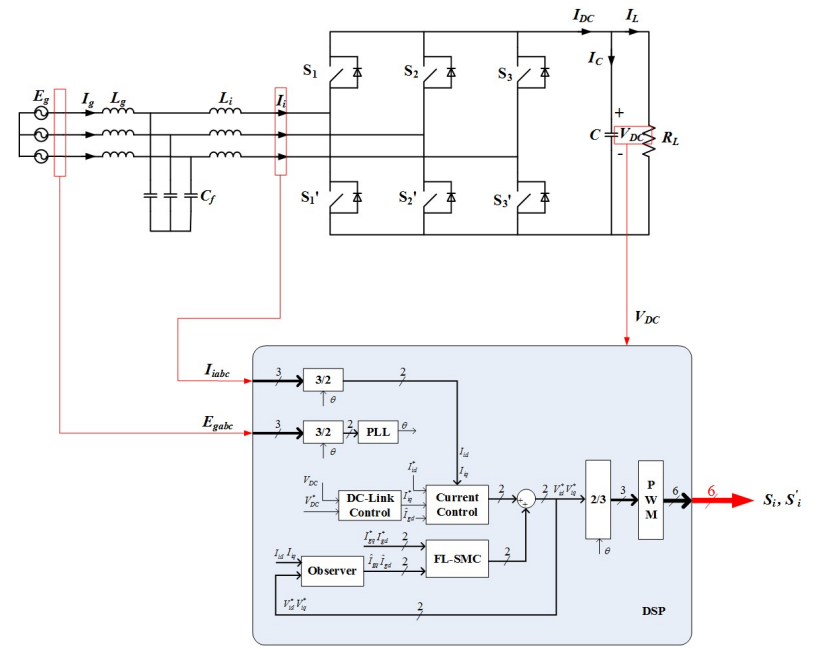

Figure 3. Control block diagram of proposed FL-SMC resonant control with observer.

\subsection{Feedback Linearization}

Feedback linearization is a technique that reduces the nonlinearity of nonlinear systems, in which an equivalent model including nonlinearity can be switched to a linear model [11]. In order to design a controller that reduces the resonance frequency component, in the differential equation of equation (1), when the differential equation of the grid current is expressed as a state equation like equation (4), it is to be equation (5).

$$
\begin{array}{rlrl}
\dot{\mathbf{x}} & =\mathbf{f}(x)+\mathbf{g} u & \mathbf{x}, \mathbf{u} \in \mathbf{R}^{n} \\
\mathbf{y}=\mathbf{h}(x) & y \in \mathbf{R}^{m}
\end{array}
$$

$$
\begin{gathered}
{\left[\begin{array}{c}
\dot{i}_{g d} \\
\dot{i}_{g q}
\end{array}\right]} \\
=\left[\begin{array}{c}
\frac{1}{L_{g}} E_{g d}-\frac{R_{g}}{L_{g}} i_{g d}+\omega \cdot i_{g q} \\
\frac{1}{L_{g}} E_{g q}-\frac{R_{g}}{L_{g}} i_{g q}-\omega \cdot i_{g d}
\end{array}\right]+\left[\begin{array}{cc}
-\frac{1}{L_{g}} & 0 \\
0 & -\frac{1}{L_{g}}
\end{array}\right]\left[\begin{array}{c}
V_{c d} \\
V_{c q}
\end{array}\right] \\
\mathbf{f}(\mathbf{x})=\left[\begin{array}{c}
\frac{1}{L_{g}} E_{g d}-\frac{R_{g}}{L_{g}} i_{g d}+\omega \cdot i_{g q} \\
\frac{1}{L_{g}} E_{g q}-\frac{R_{g}}{L_{g}} i_{g q}-\omega \cdot i_{g d}
\end{array}\right] \\
\mathrm{g}=\left[\begin{array}{cc}
-\frac{1}{L_{g}} & 0 \\
0 & -\frac{1}{L_{g}}
\end{array}\right]
\end{gathered}
$$

Here it is possible to define the state variables as $\mathbf{x}=\left[\begin{array}{cc}i_{g d} & i_{g q}\end{array}\right]^{T}$, the output as $\mathbf{y}=\mathbf{h}(\mathbf{x})=\left[\begin{array}{ll}i_{g d} & i_{g q}\end{array}\right]^{T}$, and the control input as $\mathbf{u}=\left[\begin{array}{ll}V_{c d} & V_{c q}\end{array}\right]^{T}$.

The input-output feedback linearization is applied using equa- 
tion (9). The differentiation is repeatedly applied to the output until the input is revealed, and the number of differentiations is called the relative degree. For example, the relative degree of equation (6) is 1 because the input of the equation is revealed by one differentiation.

$$
\begin{aligned}
y_{i}^{\left(r_{i}\right)}= & L_{f}^{r_{i}} h_{i}(x)+\sum_{j}^{m} L_{g_{j}} L_{f}^{r_{i}-1} h_{i}(x) u_{j}, \\
& 1 \leq \forall j \leq m, \forall r_{i} \geq \rho_{i}, 1 \leq \forall i \leq m, \forall x \in R^{n}
\end{aligned}
$$

Herein, $\rho_{i}$ is the relative degree, and $r_{i}$ is the number of differentiations.

When the differential on the first output is organized considering the relative degree, it is as follows:

$$
\begin{gathered}
L_{f} h_{1}(x)=\frac{d h_{1}(x)}{d x} f(x)=\frac{1}{L_{g}} V_{g d}-\frac{R_{g}}{L_{g}} i_{g d}+\omega \cdot i_{g q} \\
L_{g_{1}} h_{1}(x) u_{1}=\frac{d h_{1}(x)}{d x} g_{1}(x) u_{1}=-\frac{1}{L_{g}} u_{1} \\
L_{g_{2}} h_{1}(x) u_{2}=\frac{d h_{1}(x)}{d x} g_{2}(x) u_{2}=0 \\
\dot{y}_{1}=\frac{1}{L_{g}} E_{g d}-\frac{R_{g}}{L_{g}} i_{g d}+\omega i_{g q}-\frac{1}{L_{g}} u_{1}
\end{gathered}
$$

When the differential on the second output is organized considering the relative degree, it is as follows:

$$
\begin{gathered}
L_{f} h_{2}(x)=\frac{d h_{2}(x)}{d x} f(x)=\frac{1}{L_{g}} V_{g q}-\frac{R_{g}}{L_{g}} i_{g q}-\omega \cdot i_{g d} \\
L_{g_{1}} h_{2}(x) u_{1}=\frac{d h_{2}(x)}{d x} g_{1}(x) u_{1}=0 \\
L_{g_{2}} h_{2}(x) u_{2}=\frac{d h_{2}(x)}{d x} g_{2}(x) u_{2}=-\frac{1}{L_{g}} u_{2} \\
\dot{y}_{2}=\frac{1}{L_{g}} E_{g q}-\frac{R_{g}}{L_{g}} i_{g q}-\omega \cdot i_{g d}-\frac{1}{L_{g}} u_{2}
\end{gathered}
$$

Using equations (14) and (17), when the linearized state equation is to be written again, it is as follows:

$$
\begin{gathered}
{\left[\begin{array}{c}
\dot{y}_{1} \\
\dot{y}_{2}
\end{array}\right]=\mathbf{A}(x)+\mathbf{E}(x)\left[\begin{array}{c}
u_{1} \\
u_{2}
\end{array}\right]} \\
{\left[\begin{array}{c}
\dot{y}_{1} \\
\dot{y}_{2}
\end{array}\right]=\left[\begin{array}{c}
\frac{1}{L_{g}} E_{g d}-\frac{R_{g}}{L_{g}} i_{g d}+\omega i_{g q} \\
\frac{1}{L_{g}} E_{g q}-\frac{R_{g}}{L_{g}} i_{g q}-\omega i_{g d}
\end{array}\right]} \\
+\left[\begin{array}{cc}
-\frac{1}{L_{g}} & 0 \\
0 & -\frac{1}{L_{g}}
\end{array}\right]\left[\begin{array}{c}
u_{1} \\
u_{2}
\end{array}\right]
\end{gathered}
$$

$$
=\left[\begin{array}{l}
\gamma_{1} \\
\gamma_{2}
\end{array}\right]
$$

When equation (19) is organized about the control input:

$$
\begin{aligned}
& {\left[\begin{array}{l}
u_{1} \\
u_{2}
\end{array}\right]=E^{-1}(x)\left[-A(x)+\left[\begin{array}{l}
\gamma_{1} \\
\gamma_{2}
\end{array}\right]\right]} \\
& \quad=\left[\begin{array}{c}
E_{g d}-R_{g} i_{g d}+\omega L_{g} i_{g q}-L_{g} \gamma_{1} \\
E_{g q}-R_{g} i_{g q}-\omega L_{g} i_{g d}-L_{g} \gamma_{2}
\end{array}\right]
\end{aligned}
$$

When equation (20) is rewritten by substituting the input of the state equation, the linearized state equation can be obtained, and $\gamma_{i}$ becomes a new control variable.

\subsection{Sliding Mode Control}

A sliding mode surface is composed of an equation that satisfies $S_{i}(x)=0$ on the $\mathbf{R}^{n}$ flat surface [12].

$$
S_{i}(x)=\left(\frac{d}{d t}+\lambda_{i}\right)^{\gamma_{i}-1} e_{i}(x)
$$

Herein, $\gamma_{i}$ is the relative degree of the state variable taken as the output state, $e_{i}(x)$ is the output error according to the state, $\lambda_{i}$ is a positive constant, and $S_{i}(x)$ is the desired sliding surface.

Since the relative degree is 1 , the sliding surface can be defined as follows:

$$
\left[\begin{array}{l}
S_{1} \\
S_{2}
\end{array}\right]=\left[\begin{array}{l}
e_{1} \\
e_{2}
\end{array}\right]=\left[\begin{array}{c}
i_{g d}^{*}-i_{g d} \\
i_{g q}^{*}-i_{g q}
\end{array}\right]
$$

In order to converge an error value to the sliding surface in the sliding mode control, equation (23) should be satisfied:

$$
\left[\begin{array}{c}
\dot{S}_{1} \\
\dot{S}_{2}
\end{array}\right]=\left[\begin{array}{c}
\dot{e}_{1} \\
\dot{e}_{2}
\end{array}\right]=\left[\begin{array}{c}
\dot{i}_{g d}^{*}-\dot{i}_{g d} \\
i_{g q}^{*}-\dot{i}_{g q}
\end{array}\right]=\left[\begin{array}{l}
0 \\
0
\end{array}\right]
$$

When substituting the differential equation on grid current into equation (23), it is possible to determine the control input of equation (20) and the control input of the equivalence.

$$
\left[\begin{array}{c}
u_{1_{e q}} \\
u_{2_{e q}}
\end{array}\right]=\left[\begin{array}{c}
E_{g d}-R_{g} i_{g d}+\omega L_{g} i_{g q}-L_{g} \dot{i}_{g d}^{*} \\
E_{g q}-R_{g} i_{g q}-\omega L_{g} i_{g d}-L_{g} \dot{i}_{g q}^{*}
\end{array}\right]
$$

The control rules of the sliding mode control can be defined as follows:

$$
\left\{\begin{array}{l}
u_{1}=u_{1_{e q}}-K_{1} \operatorname{sign}\left(S_{1}\right) \\
u_{2}=u_{2_{e q}}-K_{2} \operatorname{sign}\left(S_{2}\right)
\end{array}\right.
$$


The control input of the controller that reduces the resonance frequency component can be defined as follows:

$$
\begin{aligned}
& {\left[\begin{array}{l}
u_{1} \\
u_{2}
\end{array}\right]} \\
& =\left[\begin{array}{c}
E_{g d}-R_{g} i_{g d}+\omega L_{g} i_{g q}-L_{g} i_{g d}^{*} \\
E_{g q}-R_{g} i_{g q}-\omega L_{g} i_{g d}-L_{g} \dot{i}_{g q}^{*}
\end{array}\right]-\left[\begin{array}{c}
K_{1} \operatorname{sign}\left(S_{1}\right) \\
K_{2} \operatorname{sign}\left(S_{2}\right)
\end{array}\right]
\end{aligned}
$$

The grid-side $q$-axis current reference value is identical to the converter-side $q$-axis current reference value, which is the DC-link control output. The current reference value is zero. Because the grid-side $d$-axis current is controlled to zero, the reactive current is provided from the converter side to the filter capacitor. In addition, the reference value of the converterside $d$-axis current becomes the value of the reactive current component, which is provided to the filter capacitor.

\subsection{Stability Determination of Controller}

The stability of the controller is determined by using a Lyapunov function. A Lyapunov function candidate is defined as follows:

$$
V=\frac{1}{2} S^{T} S, \quad V>0
$$

When the partial derivative from the Lyapunov function candidate regarding $S$ has a negative definition, it is asymptotically stable $[13,14]$.

$$
\begin{aligned}
\dot{V} & =\frac{\partial V}{\partial S_{1}} \dot{S}_{1}+\frac{\partial V}{\partial S_{2}} \dot{S}_{2} \\
& =S_{1} \dot{S}_{1}+S_{2} \dot{S}_{2} \\
& =S_{1}\left(-K_{1}^{\prime} \operatorname{sign}\left(S_{1}\right)\right)+S_{2}\left(-K_{2}^{\prime} \operatorname{sign}\left(S_{2}\right)\right) \\
& =-S_{1} K_{1}^{\prime} \operatorname{sign}\left(S_{1}\right)-S_{2} K_{2}^{\prime} \operatorname{sign}\left(S_{2}\right) \\
& =-K_{1}^{\prime}\left|S_{1}\right|-K_{2}^{\prime}\left|S_{2}\right|
\end{aligned}
$$

It is asymptotically stable since $K_{1}^{\prime}, K_{2}^{\prime}>0$ is always $\dot{V}<$ 0 .

\subsection{Recursive Suboptimum Observer}

In order to estimate the grid current, the observer is designed by using an extended Kalman filter. The state equation is determined by using the differential equation of equation (1), to which discretization is applied as follows. At this point, the grid voltage is assumed as a disturbance.

$$
\mathbf{x}_{k+1}=\mathbf{A}_{d} \cdot \mathbf{x}_{k}+\mathbf{B}_{d}^{1} \cdot \mathbf{u}_{k}+\mathbf{B}_{d}^{2} \cdot \mathbf{u}_{k}^{e}+\mathbf{w}_{k}
$$

$$
\begin{aligned}
& \mathbf{A}_{d}= \\
& \left.\begin{array}{cccccc}
1-\frac{R_{i}}{L_{i}} T_{s} & \omega T_{s} & 0 & 0 & \frac{1}{L_{i}} T_{s} & 0 \\
-\omega T_{s} & 1-\frac{R_{i}}{L_{i}} T_{s} & 0 & 0 & 0 & \frac{1}{L_{i}} T_{s} \\
0 & 0 & 1-\frac{R_{g}}{L_{g}} T_{s} & \omega T_{s} & -\frac{1}{L_{g}} T_{s} & 0 \\
0 & 0 & -\omega T_{s} & 1-\frac{R_{g}}{L_{g}} T_{s} & 0 & -\frac{1}{L_{g}} T_{s} \\
-\frac{1}{C_{f}} T_{s} & 0 & \frac{1}{C_{f}} T_{s} & 0 & 1 & \omega T_{s} \\
0 & -\frac{1}{C_{f}} T_{s} & 0 & \frac{1}{C_{f}} T_{s} & -\omega T_{s} & 1
\end{array}\right] \\
& \mathbf{B}_{d}^{1}= \\
& \mathbf{B}_{1}^{e}=\left[\begin{array}{ccccccc}
-\frac{1}{L_{i}} T_{s} & 0 & 0 & 0 & 0 & 0 \\
0 & -\frac{1}{L_{i}} T_{s} & 0 & 0 & 0 & 0
\end{array}\right] \\
& \left.\begin{array}{ccccccc}
0 & \frac{1}{L_{g}} T_{s} & 0 & 0 & 0 \\
0 & 0 & \frac{1}{L_{g}} T_{s} & 0 & 0
\end{array}\right] \\
& \mathbf{y}_{k}=\mathbf{H}_{d} \cdot \mathbf{x}_{k}=\mathbf{z}_{k}
\end{aligned}
$$

wherein the control variable, disturbance, state variable, output variable are as follows:

$$
\begin{aligned}
& \mathbf{u}_{k}=\left[\begin{array}{ll}
V_{i d}^{k} & V_{i q}^{k}
\end{array}\right]^{T} \\
& \mathbf{u}_{k}^{e}=\left[\begin{array}{ll}
E_{g d}^{k} & E_{g q}^{k}
\end{array}\right]^{T} \\
& \mathbf{x}_{k}=\left[\begin{array}{llllll}
i_{i d}^{k} & i_{i q}^{k} & i_{g d}^{k} & i_{g q}^{k} & V_{c d}^{k} & V_{c q}^{k}
\end{array}\right]^{T} \\
& \mathbf{y}_{k}=\left[\begin{array}{ll}
i_{i d}^{k} & i_{i q}^{k}
\end{array}\right]^{T}=\mathbf{z}_{k}
\end{aligned}
$$

The extended Kalman filter is largely divided into two process. In the first process, time update, the prediction value is calculated by using equation (29). The error covariance is predicted by using equation (39):

$$
\mathbf{P}_{k+1}^{-}=\mathbf{A} \mathbf{P}_{k} \mathbf{A}^{T}+\mathbf{Q}
$$

In the second process, measurement update, the Kalman gain is calculated by equation (40) in advance:

$$
\mathbf{K}_{k}=\mathbf{P}_{k}^{-} \mathbf{H}^{T}\left(\mathbf{H} \mathbf{P}_{k}^{-} \mathbf{H}^{T}+\mathbf{R}\right)^{-1}
$$

wherein $\mathbf{R}$ is the covariance matrix of the measurement noise.

Next, in order to correct the errors of the prediction value, the estimated value is determined by using the observed value and the error of the prediction value, as shown in equation (41).

$$
\hat{\mathbf{x}}_{k}=\hat{\mathbf{x}}_{k}^{-}+\mathbf{K}_{k}\left(\mathbf{z}_{k}-H \hat{\mathbf{x}}_{k}^{-}\right)
$$




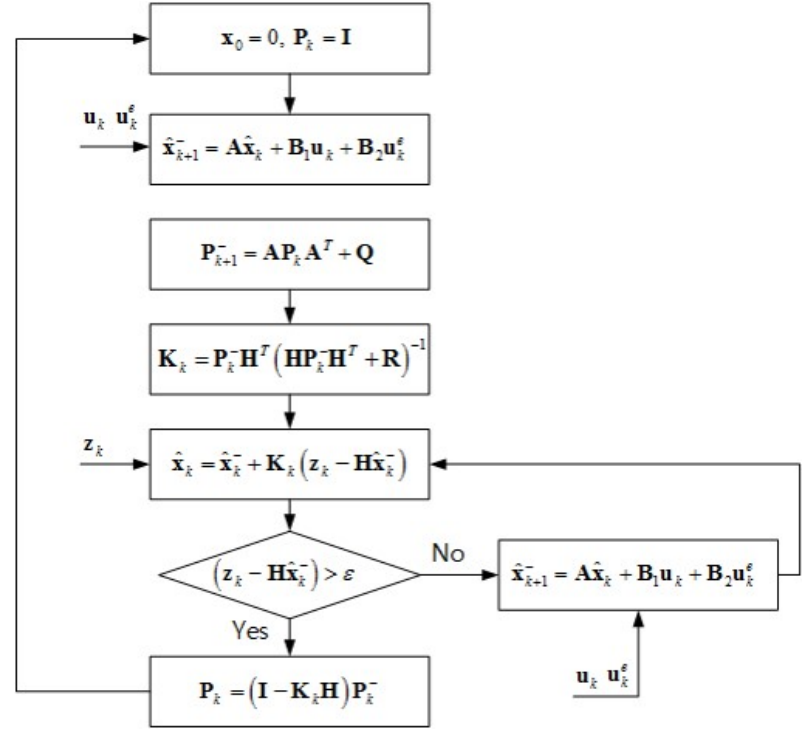

Figure 4. Flowchart of recursive steady-state Kalman filter.

wherein $\hat{\mathbf{x}}_{k}$ is the state estimation value, and $\hat{\mathbf{x}}_{k}^{-}$is the state prediction value.

By using equation (42), the covariance matrix is calculated. It is used to the next covariance matrix prediction value.

$$
\mathbf{P}_{k}=\left(\mathbf{I}-\mathbf{K}_{k} \mathbf{H}\right) \mathbf{P}_{k}^{-}
$$

By repeatedly carrying out (42) in equation (39), the Kalman gain is calculated in such a way that the error covariance becomes small.

The error covariance matrix is converged to a consistent value, with the Kalman gain also being a consistent value. At this time, the converged error covariance matrix is determined by seeking the value of an algebraic Riccati equation, while the Kalman gain can be earned by using the converged error covariance matrix. However, it is difficult to derive the value of the algebraic Riccati equation. Thus, if the error between the measurement value and the state observed variables is calculated, entering the range of allowable error, and the error covariance doesn't get to be calculated with estimating as Kalman gain of normal state.

$$
\hat{\mathbf{x}}_{k}=\hat{\mathbf{x}}_{k}^{-}+\mathbf{K}_{\infty}\left(\mathbf{z}_{k}-\mathbf{H} \hat{\mathbf{x}}_{k}^{-}\right)
$$

\section{Simulation Results}

In order to confirm the performance of the proposed controller and the observer, a simulation is conducted using PSIM 9.0.
Table 1. Simulation and Experimental System Parameters

\begin{tabular}{clc}
\hline Symbol & Quantity & Value \\
\hline$E_{g}$ & Grid voltage & $380[\mathrm{~V}]$ \\
$V_{d c}$ & DC-link voltage & $640[\mathrm{~V}]$ \\
$C_{d c}$ & DC-capacitance & $1600[\mathrm{uF}]$ \\
$L_{g}$ & Grid-side inductor & $600[\mathrm{uH}]$ \\
$L_{i}$ & Converter-side inductor & $600[\mathrm{uH}]$ \\
$C_{f}$ & Filter capacitance & $3 * 22.5[\mathrm{uF}]$ \\
$f_{\text {grid }}$ & Grid frequency & $60[\mathrm{~Hz}]$ \\
$f_{s w}$ & Switching frequency & $2.5[\mathrm{kHz}]$ \\
$T_{c}$ & Control period & $200[\mu \mathrm{s}]$ \\
$P_{\text {rate }}$ & Nominal power & $10[\mathrm{~kW}]$ \\
\hline & &
\end{tabular}

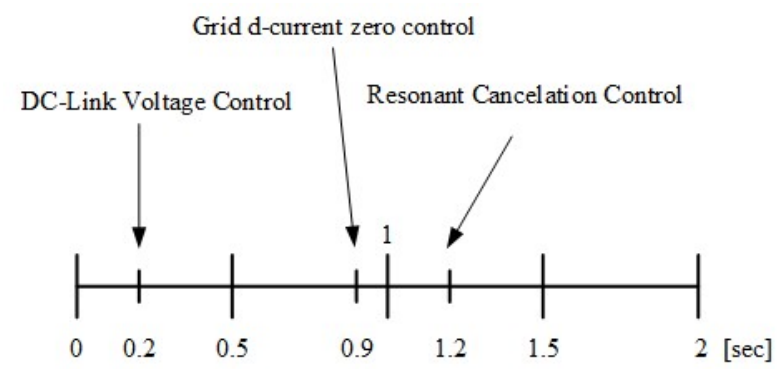

Figure 5. Simulation scenario.

The system parameters used in the simulation are listed in Table 1. The scenario of the simulation, as shown in Figure 5, first sets the DC-link voltage control at $0.2 \mathrm{~s}$, the PF control of the grid side at $0.9 \mathrm{~s}$, and the resonance control at $1.2 \mathrm{~s}$.

Figure 6 shows the waveform comparing the observed state variables with the actual measured values. Regarding the measured variables, which are observed with few errors, all state variables are observed.

Figure 7 shows the converter-side $d$ - $q$ axis current and the grid-side current. The ripple that appears in the converter-side current and the grid-side current is the component revealed by the resonance frequency of the filter. By starting to control the $\mathrm{PF}$ of the grid side at $0.9 \mathrm{~s}$ and providing the reactive current from the THD converter side to the THD filter capacitor, the $d$-axis current is controlled to a consistent value, and the $d$-axis current of the grid side is controlled to zero. It is possible to confirm that the resonance component is reduced as shown in Figure 7 from starting FL-SMC resonant control at $1.2 \mathrm{~s}$. 


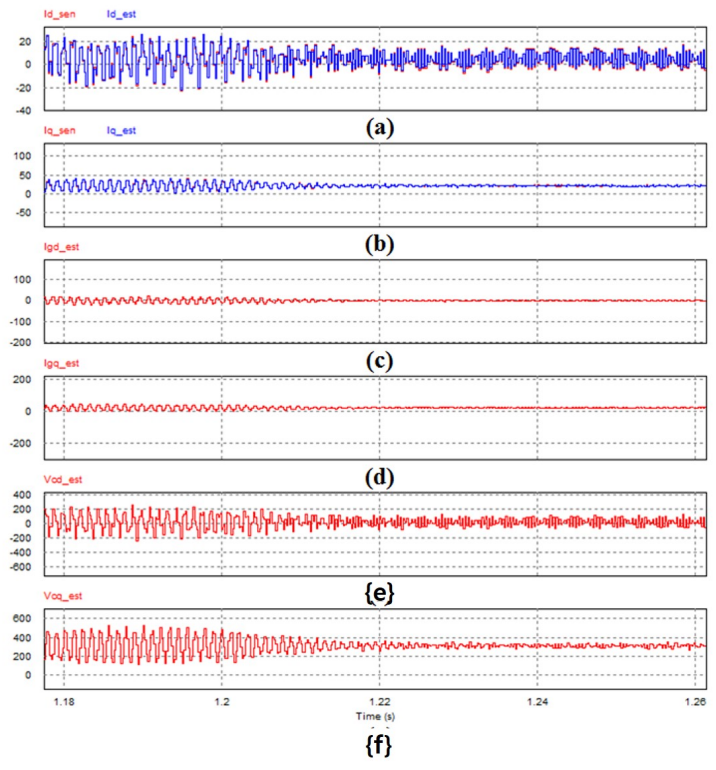

Figure 6. Comparison between measured and observed state variables: (a) converter-side $d$-axis current; (b) converter-side $q$-axis current; (c) grid-side $d$-axis current; (d) grid-side $q$-axis current; (e) filter capacitor $d$-axis voltage; (f) filter capacitor $q$-axis voltage.

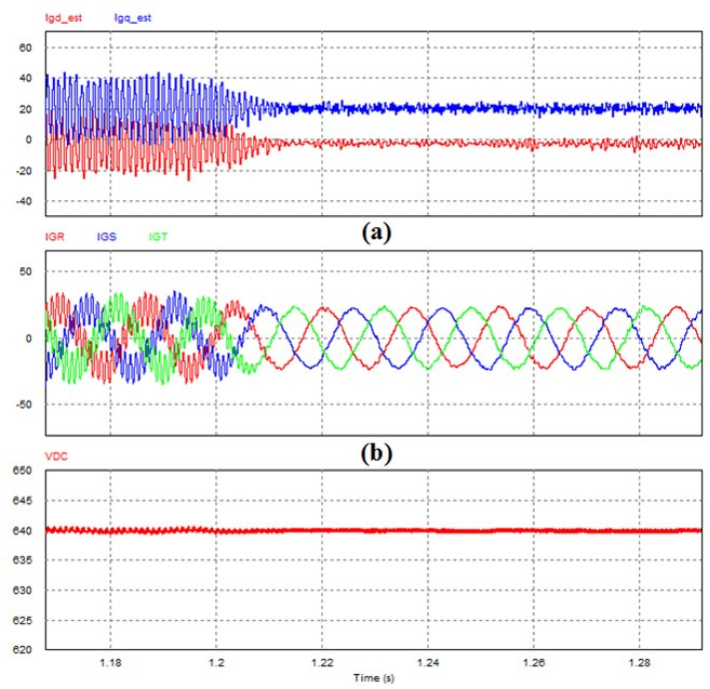

(c)

Figure 7. Characteristic of FL-SMC resonance control: (a) grid $d-q$ current; (b) grid-side three-phase current; (c) DC-link voltage.

\section{Conclusions}

This paper proposes an active damping control method for a grid-side converter with an LCL grid filter in the back-to-back converter. Generally, a power converter measures the current of the converter side for current control. Because the power converter controls the reactive current of the grid side to zero, the reactive current is input to the capacitor of the filter on the grid side. Because the power factor of the grid side worsens, the power quality also worsens due to the resonance frequency component of the LCL filter. This paper proposed a method to enhance the efficiency of the system and the power quality by accomplishing the following: control the PF of the grid side to \pm 1 by applying a grid current observer by using a recursive suboptimum observer, and remove the resonance frequency component of the LCL filter by using a resonant controller. The performance of the proposed observer is verified by confirming the errors between the measured current waveform and the observed current waveform. This is done by installing a current sensor on the grid side. In addition, it is confirmed that the FL-SMC resonant controller removes the resonant frequency component by analyzing the frequency of the grid current. The active power filter that removes not only the LCL filter resonance frequency, but also the generating harmonics at the grid requires additional study. Future research is expected to focus on these topics.

\section{Conflict of Interest}

No potential conflict of interest relevant to this article was reported.

\section{Acknowledgement}

This work was supported by BK21PLUS, Creative Human Resource Development Program for IT Convergence.

\section{References}

[1] I. J. Gabe, V. F. Montagner, and H. Pinheiro, "Design and implementation of a robust current controller for VSI connected to the grid through an LCL filter," IEEE Trans. Power Electron., vol. 24, no. 6, pp. 1444-1452, 2009.

[2] Y. Tang, P. C. Loh, P. Wang, F. H. Choo, F. Gao, and F. Blaabjerg, "Generalized design of high performance shunt active power filter with output LCL filter," IEEE Trans. Ind. Electron., vol. 59, no. 3, pp. 1443-1452, 2012.

[3] L. Xiao, Y. Lei, Z. Wang, and X. Zheng, "Optimisation of LCL filter based on closed-loop total harmonic distortion calculation model of the grid-connected inverter," IET Power Electron., vol. 8, no. 6, pp. 860-868, 2015. 
[4] M. Liserre, F. Blaabjerg, and R. Teodorescu, "Grid impedance estimation via excitation of LCL-filter resonance," IEEE Trans. Ind. Appl., vol. 43, no. 5, pp. 14011407, 2007.

[5] W. Wu, Y. He, T. Tang, and F. Blaabjerg, "A new design method for the passive damped LCL and LLCL filterbased single-phase grid-tied inverter," IEEE Trans. Ind. Electron., vol. 60, no. 10, pp. 4339-4350, 2013.

[6] G.-B. Koo, J.-B. Park, and Y.-H. Joo, “Observer-based sampled-data controller of linear system for the wave energy converter,’ Int. J. Fuzzy Log. Intell. Syst., vol. 11, no. 4, pp. 275-279, 2011.

[7] D. Fr?nken, K. Meerk?tter, and J. Wa?muth, "Observerbased feedback linearization of dynamic loudspeakers with Ac amplifiers," IEEE Trans. Speech Audio Process., vol. 13, no. 2, pp. 233-242, 2005.

[8] M. Liserre, F. Blaabjerg, and S. Hansen, "Design and control of an LCL-filter-based three-phase active rectifier," IEEE Trans. Ind. Appl., vol. 41, no. 5, pp. 1281-1291, 2005.

[9] G. I. With, O. Lcl, Z. Zou, S. Member, Z. Wang, M. Cheng, and S. Member, "Modeling, Analysis, and Design of Multifunction," vol. 29, no. 7, pp. 3830-3839, 2014.

[10] L. Peng, Q. Liu, Y. Kang, S. Tang, D. Wu, and Y. Qi, “A Novel Design and Optimization Method of LCL Filter for Shunt Active Power Filter," IEEE Trans. Ind. Electron., vol. 61, no. 8, pp. 4000-4010, 2014.

[11] J. Arif, S. Ray, and B. Chaudhuri, "Multivariable selftuning feedback linearization controller for power oscillation damping," IEEE Trans. Control Syst. Technol., vol. 22, no. 4, pp. 1519-1526, 2014.

[12] T. S. T. Shaocheng, C. T. C. Tianyou, and S. C. S. Cheng, "Adaptive fuzzy sliding mode control for nonlinear systems," Proc. IEEE 5th Int. Fuzzy Syst., vol. 1, no. 1, pp. 12-18, 1996.

[13] S.-H. Yu, C.-H. Hyun, and M.-N. Park, "Backstepping Control and Synchronization for 4-D Lorenz-Stenflo
Chaotic System with Single Input," Int. J. Fuzzy Log. Intell. Syst., vol. 11, no. 3, pp. 143-148, 2011.

[14] S.-H. Yu, C.-H. Hyun, and M.-G. Park, "Control and Synchronization of New Hyperchaotic System using Active Backstepping Design,” Int. J. Fuzzy Log. Intell. Syst., vol. 11, no. 2, pp. 77-83, 2011.

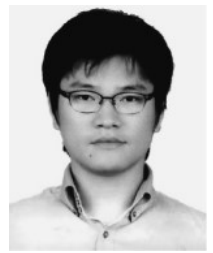

Jin-Su Gwon received the B.S. and M.S. degrees in Information and Communication Engineering from Kyungnam University, Masan, Korea, in 2009 and 2011, respectively, and is currently pursuing the Ph.D. degree in electrical engineering at Pusan National University, Busan, Korea. Since 2009, he has been with KERI, Changwon, Korea. His present interests include control of HVDC, multilevel converters, and renewable energy.

E-mail: limpnirvana@gmail.com

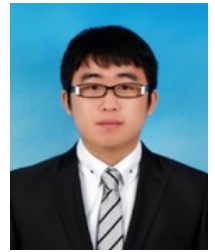

Hansoo Lee received the B.S. and M.S. degrees in Department of Electrical and Computer Engineering from Pusan National University, Busan, Korea, in 2010 and 2013, respectively, and is currently pursuing the Ph.D. degree in Electrical and Computer engineering at Pusan National University, Busan, Korea. His present interests include intelligent system and data mining.

E-mail: hansoo@pusan.ac.kr

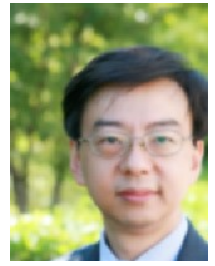

Sungshin Kim received his B.S. and M.S. degrees in Electrical Engineering from Yonsei University, Korea, in 1984 and 1986, respectively, and his Ph.D. degree in Electrical Engineering from the Georgia Institute of Technology, USA, in 1996. He is currently a professor at the Electrical Engineering Department, Pusan National University. His research interests include fuzzy logic controls, neuro fuzzy systems, neural networks, robotics, signal analysis, and intelligent systems.

E-mail: sskim@pusan.ac.kr 